\title{
Challenges in Teaching Information Literacy in Online Courses
}

\author{
Vilve Seiler
}

University of Tartu Library, subject librarian

Abstract: This paper discusses the models of teaching information literacy at the University of Tartu. The library offers two general e-learning courses: Fundamentals of information literacy as an optional subject for baccalaureus and master's students and Introduction to information research as an elective subject for doctoral students. Based on the basic course, subject librarians offer discipline-specific online courses which are taught as a part of some subjects and are compulsory for students.

Keywords: information literacy, academic libraries, teaching library, e-learning

\section{Introduction}

During recent years, the amount of literature on information literacy has been growing, different approaches to information literacy education have been discussed and information literacy has become an issue at many academic libraries.

There are many definitions of information literacy. The definition presented in this paper is the one provided by the American Library Association, which has been most cited: "To be information literate, a person must be able to recognize when information is needed and have the ability to locate, evaluate and use effectively the needed information" (ALA, 1989).

Information literacy is topical right now because, in relation with the reforms of higher education, ongoing in European countries, the learning outcomes are very important and outcomes-based curricula are being designed everywhere. Teaching of information literacy has a direct effect on the students' study results, as these skills support such outcomes as critical thinking, solving of problems and lifelong learning. Information literacy enables to improve the quality of studying and helps the students to become life-long learners. People who can search for information and evaluate and organise information are more successful in their studies and later, in their career; they are selfdirected learners, much valued by society. (Rockman, 2004).

This paper discusses the challenges of implementing information literacy education at the University of Tartu, Estonia (www.ut.ee). First, the conception of the stand-alone e-learning course Fundamentals of information literacy is described, then the teaching and learning approaches are discussed; the paper ends with examples of the students' responses to the course.

The design and implementation of the information literacy course was a challenging task that was meant to find an answer to the questions whether such 
a course, developed at the library, could find positive response at the university, whether it would attract students and whether the students would appreciate the knowledge acquired during the course and, last but not least, whether librarians would be able to teach such a course. We also wanted to find assurance whether an e-course as a form of teaching and learning would be suitable for teaching information literacy. Our experience could be useful for other academic libraries who wish to use e-courses in teaching information literacy and to formalise information literacy education.

\section{Initiative of teaching library - stand-alone information literacy e- learning course}

The mission of the University of Tartu Library (www.utlib.ee) is, by developing its collections, to offer the best library and information services and be a trustworthy partner to the members of the University of Tartu and other library users in supporting their teaching and learning, research and professional careers.

To facilitate access to information, the library licences to valuable and expensive digital resources. In order to benefit from these resources at their fullest, the students have to obtain information literacy. Very often the librarians can see that students do not know professional databases relevant for their specialities and are not familiar with the ways of information search.

The university library as a provider of information resources feels the responsibility to offer students and university staff knowledge of information resources in their subject field, to enable the students to find the information they need and to improve the quality of their assignments. The aim is to teach how to use their own library and its resources, but also to provide information literacy education considering the ALA definition, according to which information literacy education is wider than teaching of specific information resources - it also includes critical thinking skills and the evaluation of the information sources.

Numerous discussions on how information literacy should be taught have been held in librarians' professional publications. The majority of participants of these discussions believe that teaching of information literacy should be integrated or embedded into the subjects of the curricula and the importance of cooperation between the faculties and the library is much stressed. Some authors, such as Johnston and Webber (2003) and Owusu-Ansah (2004), argue that information literacy could be a subject in its own right and it can be taught in the form of stand-alone courses. Owusu-Ansah (2004: 12) is convinced that "the library should offer an independent credit course in information literacy, one that offers in depth engagement with issues inherent in and skills attendant to information literacy".

In order to demonstrate the need for information literacy at the university and to draw attention to it as a possible curriculum subject, and to give students the opportunity to develop more in depth information literacy skills and abili- 
ties, we decided, first, to design a basic course in information literacy and later, to use all possible means to integrate the teaching of this course into different curricula and subjects. In 2006, we developed a web-based course Fundamentals of Information Literacy. It is a credit-bearing optional course, giving two credit points ( 3 ECTS). The course is suitable for all specialities, as it is related with the virtual subject area libraries of the University of Tartu Library and it is taught by the subject librarians of the library, who supervise the students of their specialities. The learning modules were designed bearing in mind the needs of both the beginners and advanced learners and all students receive individual tutoring. The course is especially suitable for Bachelor's and Master's students, who already have their own research subject and specific information needs.

In 2008, a continuation course was designed for the target group of advanced learners, which has been included into all curricula of doctoral students of the university. The curricula of doctoral studies prescribe for all-university key competence subjects, in the amount of eight credit points; information literacy as an essential key competence has been included among them.

\section{Why e-learning?}

E-courses allow teaching of a large number of students and offer a more extensive programme than a traditional course, restricted by time limit, usually requested from the library. As the participants come from different faculties, the flexibility of an e-course is a great advantage and all participants can study at their most suitable time and place. At a web-course, it is easier to consider the needs of both the beginners and the advanced learners; the chapters of the course are built in gradation and the learner can choose which part of it he/she wants to study more thoroughly. Information search is a process and the result can be achieved by different paths. Feedback from the forum of the course allows drawing attention to different possibilities in such a way that all participants can benefit from it.

\section{Teaching and learning approach}

The course programme was designed in accordance with the ACRL-developed information literacy standards for higher education. (ACRL, 2000) These five standards, together with performance indicators and learning outcomes, cover the whole range of information literacy and present possible spheres of activities, where libraries can participate in the teaching of information literacy.

\section{Learning modules}

In e-courses, the good structure of materials - so that they were comprehensive and quick to learn - is of essential nature. Material is thematically ordered, but it is not necessary to read the chapters in a rigid order. - they are structured and necessary parts can easily be reread when doing the exercises. We did not aim at compiling detailed materials on the use of specific databases, but wanted 
to introduce the types of different databases and general search principles so that the graduates of the course would in the future be able to search new databases on their own.

The course consists of 13 modules, discussing types of information sources, principles of information search, types and structure of databases, advanced search in different search environments accessible for the University of Tartu Library, possibilities for searching scientific information on the Internet, as well as the evaluation of information sources and the avoiding of plagiarism.

\section{Study process}

The whole course is carried out in the virtual learning environment Blackboard, where the students can find the materials, submit their homework, communicate with the tutors and with each other, and get feedback. E-course can succeed only if the whole study process has been carefully planned.

At the beginning of the course, a week is set aside for getting familiar with the environment and the course and for the students and tutors to get acquainted with each other in order to support the forming of a group. Starting from the second week, the participants practice information search on their subject according to the course plan and submit their work to respective forums, where they can get feedback. For example, in the first exercise, the students have to find, with the help of virtual subject libraries, the EBSCO and CSA databases that are relevant to their subject, get acquainted with them, describe in detail and analyse their search strategies for keyword and subject heading search and compare the suitability of both searches for their subject. Next exercises contain searches in other professional databases; by the end of the course, the students have obtained an overview of all databases and learned how to collect database entries which are relevant for their subjects. During the last week of the course, they write a review of all of their searches and analyse and reflect upon their learning process and successes, and submit a bibliography, formulated according to the system of referencing that they had chosen.

\section{Pedagogical approach}

The course is based on the constructivist treatment of learning that positions the student in the centre of the learning process. While choosing the activities for the course, we paid much attention to the activating methods and problembased learning. Self-directed learning is the most important activating strategy for the web-based learning, making the learner responsible for his/her motivation and awareness (Pitt and Clark, 2006).

In our course model, we also applied elements of the relational frame for information literacy education, introduced by Bruce, Edwards and Lupton (2006), who underline that reflection and planning of the search process are the key aspects of the searching experience and that search planning and active searching reflection influences the quality of the search performance.

We also drew from the action research model for Reflective Internet Search- 
ing, presented by Edwards and Bruce (2002), which shows online searching as a circle of continuous planning, acting, recording and reflecting. In all information search exercises of the course, the students give detailed records of their searches, describe different versions of the searches and analyse, which search strategy gave the most relevant results, and in the final review, reflect the whole of their learning process.

Studying at the information literacy course is flexible and the learners can control their learning process. They can choose when and what to learn, selecting just the materials they want to study and centring upon them. Practical exercises are flexible as well, meaning that certain conditions have to be fulfilled, but the subject and the information sources can be chosen by the learner and thus, the learners have greater freedom and responsibility of interpreting the course. The exercises submitted by the students can be read by all participants of the course and checking of other learners' ideas together with the feedback from the tutor can add value to learning. In such a way, all learners create new content for the course, which is accessible for all of their fellow students.

The learners mostly work independently; the developing of independence and critical thinking has an important role in the course. Information search skills are developed by practicing different searches and in interaction with the tutor. In order to support other ways of learning, we have, in some exercises, used collaborative learning.

Giving feedback is a time-consuming activity, it has to be constructive and support the learner. Advisory feedback is especially valuable during the learning process, as it motivates the learners and helps them to get better results. Usually, one tutor supervises 10-15 students during the course, which is the optimal number. The tutor is not an expert in certain specialities, but he/she knows databases, has a vast experience of information search and can offer valuable suggestions. The role of the tutor is, rather, that of an advisor and moderator in learning and information processes, according to Ingraham, Levy, McKenna and Roberts (2006: 166), "it shifts away from direct instruction towards strategies that will facilitate those dialogical interactions between learner and tutor, and between learners, that are the heart of constructivist and relational pedagogies".

In order to reduce the workload of tutors, it is possible to use peer-tutoring. However, when using peer-tutoring, the students need to be given precise criteria and guidelines for their activities. We first used this method at an advanced course, and the concentration of doctoral students onto the subjects and search processes of their fellow learners exceeded our expectations. This method also helps to unify the learners into a group, it motivates and activities them and develops their critical skills in evaluating their own, as well as their fellows' work.

Students' perceptions

In order to get evaluation of the course, we asked the participants to express 
their thoughts about the materials, exercises, schedule and the activities of the tutors in an anonymous forum, and to state, whether the course met their needs and expectations. The students wrote free text about what the course had given to them. Many participants expressed their views about the course in the review of the final week, where they analysed their learning process. Of 215 students, who passed the course Fundamentals of Information Literacy, 107 gave feedback about the course and all of them were sure that it had been necessary and useful, were happy that they had chosen the course and several of them admitted, that such a course would have been vital for them already earlier. $37 \%$ of them said that they found information about new databases and services they had previously not been aware of. Many students admitted that, prior to the course, they had used only the library e-catalogue and the Internet. $21 \%$ of the participants mentioned that during the course, they much improved their knowledge of different search methods and search skills. During the course, it was well visible how the participants' skills in planning their searches improved. $28 \%$ of the participants said that due to the information literacy course, they have better chances in writing a good bachelor's or master's thesis, as they are much better able to search for and choose information sources. Some of the participants said that the acquired skills help them in their career as well.

The structure of the course was praised by $36 \%$ of the participants. They said that the course is flexible and student-friendly and well suitable for selfstudy, as it allows for studying whenever it is convenient. "Independent searching and analysis were the most important parts of the course, as this is the best way of learning something." The reading of works of fellow learners was also considered important, as "it gives you the feeling that you are not alone in taking the course." Individual and quick feedback is much appreciated by the students, who repeatedly used the words quick, efficient, practical, positive, advancing, supporting, and useful in their commentaries. The experience of studying on the Internet and using Blackboard was appreciated as well. The participants expressed the idea that the teaching of information search should be included in the curriculum of the 2nd and 3rd year bachelor's studies.

A participant of the course drew the following conclusion, "Fundamentals of Information Literacy $=$ new and interesting knowledge + well compiled and clear study materials + specified criteria concerning the passing of the course + friendly tutors."

Suggestions received from the feedback have helped to continue developing the course every year. A model of such a course that centres on independent active work and furthers the development of learners' critical thinking is very time-consuming and considerably increases the tutors' workload. At the same time, students appreciate such courses where they can receive quick individual feedback; positive feedback from students, in its turn, motivates the organisers of the course and the tutors to improve the course.

In 2008, this course was given a special award in the field of socialia at the competition The e-Course of the Year of the Estonian e-University. Information 
of this successful course is spreading at the university and at several specialities a wish has been expressed to include it into the curriculum as an elective course.

\section{Courses integrated into different subjects}

In addition to stand-alone general information literacy course, some students have the opportunity of developing their information literacy within courses in their speciality. As a large part of the basic course is similar for all specialities, subject librarians can use its modules for fitting in speciality-based information literacy courses by adding speciality-specific content. Earlier, subject librarians organised seminars, requested by teaching staff, for introducing information sources and information search; the duration of these seminars was only 90 minutes. Now, it is possible to offer much more exhausting courses. Much depends on the subject librarian - if he/she is able to convince the lecturers in the benefits of such courses for the students, the opportunities for cooperation can be found.

At present, such courses, compulsory for students, are held within individual subjects at the Faculties of Law, Exercise and Sport Sciences, Education, and Social Sciences. They are carried out in the environment of e-learning face to face with the main course, they have in different ways been integrated into specialty courses, and the content and practical activities of the course are agreed upon with the lecturer of the subject. As a rule, the number of participants at these courses is large (in 2008, the total of 1270 students participated in five different courses), and it is not possible to use exercises with individual feedback. Instead, tests with automatic feedback have to be used. However, students can still elect a separate course in information literacy if they need it.

We hope to attract attention to such courses at other faculties as well and we can tailor the programme of the course according to specific needs of different faculties. E-learning gives a huge advantage here, as the faculties do not need to find special classroom time.

\section{Conclusions}

We can conclude, based on our observations of the student learning as well as on feedback from the students that both the basic and advanced courses in information literacy were successful. The courses fulfil their objective of drawing attention to information literacy at the university. This allows the library to address its objective of integrating information literacy into the university curricula. Specialty-centred information literacy courses have already been adopted at four faculties.

Not all subject librarians had had some previous experience in teaching information literacy. According to the conception of the basic course, all subject librarians had to supervise the students of their faculties, thus not only students learned from each other's exercises and commentaries - the tutors had to learn as well. As a result of the course, even those subject librarians, who were not so 
comfortable with teaching, have become information literacy specialists and tutors.

Preparation and management of an e-course is extremely labour-consuming; the forwarding of materials, communication and grading require full responsibility of the organisers. E-learning suits information literacy courses very well just for its flexibility, as the participants can plan their time, but it also requires self-discipline and motivation. Due to e-learning, it is easier to integrate information literacy modules into courses of different specialities, as the students do not need to come to the library for lectures and no special classroom time is needed.

The library continues to offer a general basic e-course Fundamentals of Information Literacy as an optional subject for students in the autumn semester, and doctoral students can elect a course Introduction to Information Research in each spring semester. The content and form of both of these courses constantly need updating.

\section{References}

ACRL (2000). Information Literacy Competency Standards for Higher Education. Available at http://www.ala.org/ala/mgrps/divs/acrl/ standards/ informationliteracycompetency.cfm; accessed 26.03.09.

ALA (1989). American Library Association. Presidential Committee on Information Literacy. Final Report. Available at http:/www.ala.org/ala/mgrps/divs/ acrl/publications/whitepapers/presidential.cfm; accessed 4.04.2009.

Bruce, C. S., Edwards, S. and Lupton, M. (2006). Six frames for information literacy education: a conceptual framework for interpreting the relationships between theory and practice, Italics, Vol. 5, No 1. Available at http://www.ics.heacademy. ac.uk/italics/vol5-1/pdf/sixframes_final\%20_1_.pdf; accessed 4.04.2009.

Edwards, S. L. and Bruce, C. S. (2002). Reflective Internet Searching: an action research model, The Learning Organization, Vol. 9, No 4, 180-188.

Ingraham, B., Levy, P., McKenna, C. and Roberts, G. (2006). Academic Literacy in the 21 st Century. Contemporary Perspectives in E-learning Research: Themes, Methods and Impact on Practice, 161-173.

Johnston, B., and Webber, S. (2003). Information literacy in higher education: a review and case study, Studies in Higher Education, Vol. 28, No 3, 335-352.

Owusu-Ansah, E. K. (2004). Information literacy and higher education: placing the academic library in the centre of a comprehensive solution, The Journal of Academic Librarianship, Vol. 30, No. 1, 3-16.

Pitt, T., and Clark, A. (2006). Creating Powerful Online Courses Using Multiple Instructional Strategies. Available at http://www.emoderators.com/ moderators/pitt.html; accessed 26.03.2009.

Rockman, I. F. (2004). Conclusion: Continuing the Dialogue. Integrating Information Literacy into the Higher Education Curriculum: Practical Models for Transformation, 237-251. 
